(Figure $1 C-D$ ). In vitro, exposure of TCR-stimulated early RA CD4+ T cells to pim kinase inhibitors restrained their activation and proliferative capacity; diminished pro-inflammatory cytokine production (IFN-g and IL-17) and an expanded CD2 ${ }^{\text {hi }}$ FoxP3 + regulatory $T$ cell (Treg) fraction were also observed in treated versus un-treated cells. Finally, administration of pim inhibitors robustly attenuated clinical scores of arthritis in the CIA model, with reduced cartilage loss observed in animals treated with a pan-PIM inhibitor compared with vehicle control (Figure 2).
A

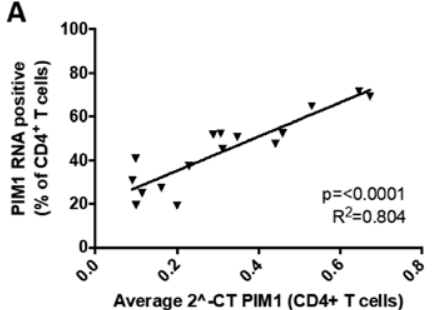

C

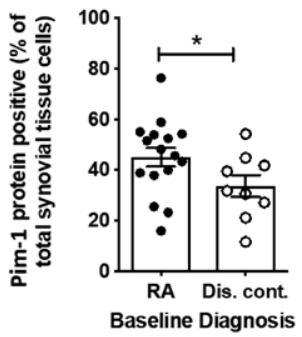

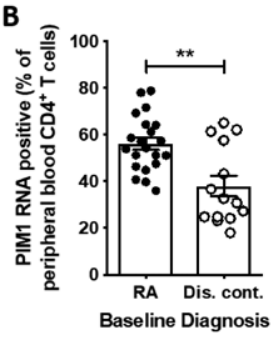

D

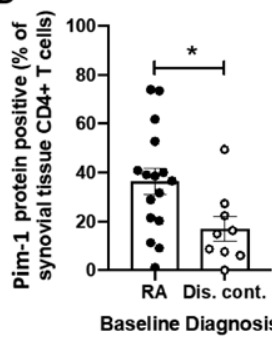

Figure 1. A. Correlation between CD4+T cell PIM1 readouts of flow cytometric assay and real-time PCR. B. PIM1 transcript in circulating RA and disease control CD4+ T cells. Quantitative immunofluorescence staining for pim-1 in (C) nucleated $(D A P I+)$ synovial cells and $(D) C D 3+C D 4+T$ cells in particular.
A

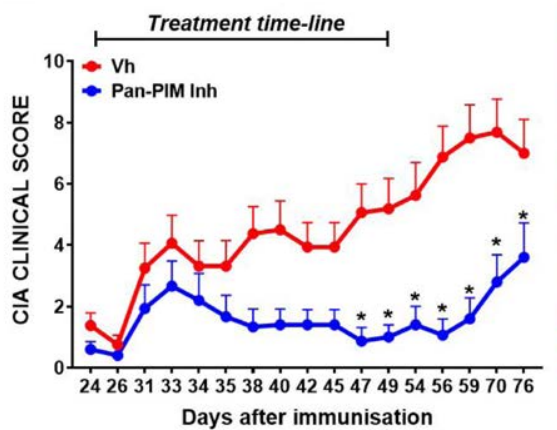

B

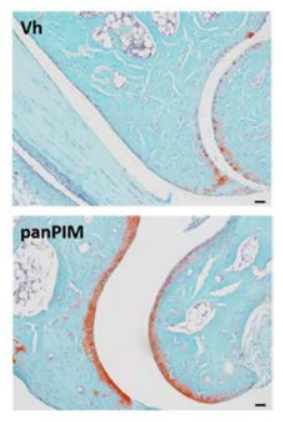

Figure 2. A. Significantly reduced arthritis severity amongst CIA mice treated with pan-pim inhibitor $(n=15)$ compared with vehicle control (Vh; $n=16)$. B. Representative images depicting preserved ankle joint cartilage layer (safranin O) following pan-pim kinase inhibition (day 50; separate experiment).

Conclusion: Our data highlight pim kinases as plausible therapeutic targets for a subgroup of early RA patients that may be identifiable using tractable in vitro assays. Pim kinase inhibitors could simultaneously target immune inflammation and RASF dysregulation; consideration should now be given to their repurposing for this condition.

References:

[1] Anderson AE et al Annals of the Rheumatic Diseases 2016; 75:466-73.

[2] Anderson AE et al Rheumatology 2019; 58:1250-1258

[3] Ha YJ et al Rheumatology 2019; 58:154-64

Disclosure of Interests: Nicola Maney Consultant of: Current employee of Eli Lilly, Henrique De Paula-Lemos: None declared, Ben Barron-Millar: None declared, Andrew Mellor Shareholder of: NewLink Genetics PLC, and has received patent licensing income from this source., John $D$ Isaacs Consultant of: AbbVie, Bristol-Myers Squibb, Eli Lilly, Gilead, Janssen, Merck, Pfizer, Roche, Amy Anderson: None declared, Arthur Pratt Grant/research support from: Pfizer, GlaxoSmithKlein

DOI: 10.1136/annrheumdis-2020-eular.2818

\section{SAT0014 ENDOTHELIAL PROGENITOR CELLS: ROLE IN ENDOTHELIAL DAMAGE OF INTERSTITIAL LUNG DISEASE ASSOCIATED TO RHEUMATOID ARTHRITIS}

V. Pulito-Cueto $^{1}$, S. Remuzgo-Martínez ${ }^{1}$, F. Genre ${ }^{1}$, V. M. Mora-Cuesta ${ }^{1}$, D. Iturbe Fernández ${ }^{1}$, S. Fernández-Rozas ${ }^{1}$, L. Lera-Gómez ${ }^{1}$, P. Alonso Lecue ${ }^{1}$, J. Rodriguez Carrio ${ }^{2}$, B. Atienza-Mateo ${ }^{1}$, V. Portilla ${ }^{1}$, D. Merino ${ }^{3}$, R. Blanco ${ }^{1}$, A. Corrales ${ }^{1}$, J. M. Cifrián-Martínez ${ }^{1}$, R. López-Mejías ${ }^{1}$, M. A. GonzálezGay ${ }^{1,4,5} .{ }^{1}$ Research Group on Genetic Epidemiology and Atherosclerosis in Systemic Diseases and in Metabolic Bone Diseases of the Musculoskeletal System, IDIVAL, Hospital Universitario Marqués de Valdecilla, Santander, Spain, Santander, Spain; ${ }^{2}$ Department of Functional Biology, Immunology Area, Faculty of Medicine, Universidad de Oviedo, Oviedo, Spain; ${ }^{3}$ Health Research Institute-IDIVAL, Santander, Spain; ${ }^{4}$ School of Medicine, Universidad de Cantabria, Santander, Spain; ${ }^{5}$ Cardiovascular Pathophysiology and Genomics Research Unit, School of Physiology, Faculty of Health Sciences, University of the Witwatersrand, Johannesburg, South Africa

Background: Interstitial lung disease (ILD) is one of the most significant comorbidities of rheumatoid arthritis (RA), increasing the mortality in these patients $[1,2]$. Although the pathogenesis of ILD associated to RA (RA-ILD ${ }^{+}$) remains poorly defined [1], it is known that vascular tissue plays a crucial role in lung physiology [3]. In this context, a population of cells termed endothelial progenitor cells (EPC) are involved in vasculogenesis and endothelial tissue repair [4]. Previous reports suggest the implication of EPC in different conditions such as RA and idiopathic pulmonary fibrosis (IPF), the most common and destructive ILD $[5,6]$. Nevertheless, little is known about their specific role in RA-ILD ${ }^{+}$.

Objectives: The purpose of this study was to shed light on the potential role of EPC in endothelial damage in RA-ILD ${ }^{+}$

Methods: Peripheral venous blood was collected from a total of 68 individuals (18 with RA-ILD ${ }^{+}, 17$ with RA-ILD', 19 with IPF and 14 healthy controls). All subjects were recruited from the Rheumatology and Pneumology departments of Hospital Universitario Marqués de Valdecilla, Santander, Spain. Quantification of EPC was analyzed by the expression of surface antigens by flow cytometry. The combination of antibodies against the stem cell marker CD34, the immature progenitor marker CD133, the endothelial marker VEGF receptor 2 (CD309) and the common leukocyte antigen CD45 was used. EPC were considered as $\mathrm{CD}_{3} 4^{+}, \mathrm{CD} 45^{\mathrm{Low}}, \mathrm{CD} 09^{+}$and $\mathrm{CD}_{133^{+}}$. All statistical analyses were performed using Prism software 5 (GraphPad).

Results: EPC frequency was significantly increased in patients with RA-ILD ${ }^{+}$ RA-ILD and IPF compared to controls $(p=0.001, p=0.002, p<0.0001$, respectively). Nevertheless, patients with RA, both RA-ILD ${ }^{+}$and RA-ILD', showed a lower frequency of EPC than those with $\operatorname{IPF}(p=0.048, p=0.006$, respectively). Conclusion: Our results provide evidence for a potential role of EPC as a reparative compensatory mechanism related to endothelial damage in RA-ILD RA-ILD and IPF patients. Interestingly, EPC frequency may help to establish a differential diagnostic between patients with IPF and those who have an underlying autoimmune disease (RA-ILD ${ }^{+}$.

\section{References:}

[1] J Clin Med 2019; 8: 2038;

[2] Arthritis Rheumatol 2015; 67: 28-38;

[3] Nat Protoc 2015; 10: 1697-1708;

[4] Science 1997; 275: 964-966;

[5] Rheumatology (Oxford) 2012; 51: 1775-1784

[6] Angiogenesis 2013; 16: 147-157.

Acknowledgments: Personal funds, VP-C: PREVAL18/01 (IDIVAL); SR-M: RD16/0012/0009 (ISCIII-ERDF); LL-G: PI18/00042 (ISCIII-ERDF); RL-M: Miguel Servet type I CP16/00033 (ISCIII-ESF).

Disclosure of Interests: Verónica Pulito-Cueto: None declared, Sara Remuzgo-Martínez: None declared, Fernanda Genre: None declared, Victor Manue Mora-Cuesta: None declared, David Iturbe Fernández: None declared, Sonia Fernández-Rozas: None declared, Leticia Lera-Gómez: None declared, Pilar Alonso Lecue: None declared, Javier Rodriguez Carrio: None declared, Belén Atienza-Mateo: None declared, Virginia Portilla: None declared, David Merino: None declared, Ricardo Blanco Grant/research support from: AbbVie, MSD, Roche, Consultant of: Abbvie, Eli Lilly, Pfizer, Roche, Bristol-Myers, Janssen, UCB Pharma and MSD, Speakers bureau: Abbvie, Eli Lilly, Pfizer, Roche, Bristol-Myers, Janssen, UCB Pharma. MSD, Alfonso Corrales Speakers bureau: Abbvie, Jose Manuel Cifrián-Martínez: None declared, Raquel López-Mejías: None declared, Miguel A González-Gay Grant/research support from: Pfizer, Abbvie MSD, Speakers bureau: Pfizer, Abbvie, MSD DOI: 10.1136/annrheumdis-2020-eular.3228

\section{SAT0015 ROCK INHIBITION REDUCES THE SEVERITY OF K BXN SERUM-TRANSFER INDUCED ARTHRITIS}

A. Rodríguez-Trillo ${ }^{1}$, N. Mosquera Garrote ${ }^{1}$, C. M. Pena Pena ${ }^{1}$, A. Mera Varela ${ }^{1}$, A. Gonzalez ${ }^{1}$, C. Conde ${ }^{1} .{ }^{1} I D I S$ - CHUS Santiago de Compostela, 